\title{
Automatic near real-time selection of flood water levels from high resolution Synthetic Aperture Radar images for assimilation into hydraulic models: a case study
}

Article

Accepted Version

Mason, D.C., Schumann, G. J.-P., Neal, J.C., Garcia-Pintado, J. and Bates, P.D. (2012) Automatic near real-time selection of flood water levels from high resolution Synthetic Aperture Radar images for assimilation into hydraulic models: a case study. Remote Sensing of Environment, 124. pp. 705-716. ISSN 0034-4257 doi: https://doi.org/10.1016/j.rse.2012.06.017 Available at https://centaur.reading.ac.uk/28642/

It is advisable to refer to the publisher's version if you intend to cite from the work. See Guidance on citing.

To link to this article DOI: http://dx.doi.org/10.1016/j.rse.2012.06.017

Publisher: Elsevier

All outputs in CentAUR are protected by Intellectual Property Rights law, including copyright law. Copyright and IPR is retained by the creators or other copyright holders. Terms and conditions for use of this material are defined in the End User Agreement. 


\section{www.reading.ac.uk/centaur}

\section{CentAUR}

Central Archive at the University of Reading

Reading's research outputs online 


\title{
Automatic near real-time selection of flood water levels from high resolution Synthetic
} Aperture Radar images for assimilation into hydraulic models: a case study

\author{
D. C. Mason 1 , G. J-P. Schumann 2 , J. C. $\mathrm{Neal}_{2}$, J. Garcia-Pintado 1 , P. D. Bates 2
} ${ }_{1}$ National Centre for Earth Observation, University of Reading, Harry Pitt Building, 3 Earley Gate, Whiteknights, Reading RG6 6AL, UK.

${ }_{2}$ School of Geographical Sciences, University of Bristol, University Road, Bristol BS8 1SS, UK.

\section{Abstract}

Flood extents caused by fluvial floods in urban and rural areas may be predicted by hydraulic models. Assimilation may be used to correct the model state and improve the estimates of the model parameters or external forcing. One common observation assimilated is the water level at various points along the modelled reach. Distributed water levels may be estimated indirectly along the flood extents in Synthetic Aperture Radar (SAR) images by intersecting the extents with the floodplain topography. It is necessary to select a subset of levels for assimilation because adjacent levels along the flood extent will be strongly correlated. A method for selecting such a subset automatically and in near real-time is described, which would allow the SAR water levels to be used in a forecasting model. The method first selects candidate waterline points in flooded rural areas having low slope. The waterline levels and positions are corrected for the effects of double reflections between the water surface and emergent vegetation at the flood edge. Waterline points are also selected in flooded urban areas away from radar shadow and layover caused by buildings, with levels similar to those in adjacent rural areas. The resulting points are thinned to reduce spatial autocorrelation using a top-down clustering approach. The method was developed using a TerraSAR-X image from a particular case study involving urban 
23 and rural flooding. The waterline points extracted proved to be spatially uncorrelated, with levels 24 reasonably similar to those determined manually from aerial photographs, and in good agreement 25 with those of nearby gauges.

26

27 Corresponding author: D. C. Mason (email: d.c.mason@ reading.ac.uk, tel: +44-118-378-8743, 28 fax: +44-118-378-6413)

29 Keywords: Flood detection, Synthetic aperture radar, Water level, Assimilation, Hydraulic 30 modelling. 


\section{Introduction}

32 Flood extents caused by fluvial floods in urban and rural areas may be predicted by hydraulic

33 models, given knowledge of the topography of the floodplain and channel together with other

34 boundary conditions that may include the input flow rate at the upstream boundary of the reach

35 being modelled and the water stage at the downstream boundary. Uncertainty in the flood extents

36 predicted may be reduced by using data assimilation to combine the model state variables with

37 observations. Assimilation may be used to correct the model state and to improve the estimates of the model parameters (e.g. channel friction) or external forcing (e.g. input flow rate).

One common observation that may be assimilated is the water level at various points along the modelled reach. Water levels may be obtained from river gauges, and assimilation of gauge water levels into models has been considered by Romanowicz et al. (2006) and Neal et al. (2007). In the UK as in many other places, a difficulty is that gauges are typically sited only every $20 \mathrm{kms}$ or so, thus giving little information on the spatial variations in the flood level, which may be particularly important in urban areas. Much more spatial information is contained in the flood extents captured in satellite SAR images. SARs are generally used for flood

47 detection rather than visible-band sensors because of their all-weather day-night capability.

48 Spatially distributed water levels may be estimated indirectly along the flood extents in SAR 49 images by intersecting the extents with a floodplain Digital Elevation Model (DEM) (Raclot 50 2006, Lane et al. 2003, Horritt et al. 2003, Schumann et al. 2007, Hostache et al. 2009).

51 Assimilation of water levels derived from SAR images of flood extent into hydraulic models has 52 been investigated by Matgen et al. (2007), Matgen et al. (2010), Giustarini et al. (2011) and Neal 53 et al. (submitted). 
54 Given that $50 \%$ of the world's rivers contain no gauges, and that the number that exist is actually

55 declining (Vorosmarty et al. 1996), a further advantage of measuring water levels from SAR

56 flood extents is that the method will work in un-gauged catchments. Direct space-borne

57 measurement of surface water level has been made in the past by the Shuttle Radar Topography

58 Mission (SRTM) (Alsdorf et al. 2007), ICESAT (Frappart et al. 2006) and altimeters such as

59 RA-2 on Envisat, and can currently be made by altimeters such as Poseidon 2 on JASON-1,

60 though the altimeter footprints are such that they are limited to level measurement in rivers $\sim 1 \mathrm{~km}$

61 wide. In the future, NASA's Surface Water and Ocean Topography (SWOT) Mission will use

$62 \quad \mathrm{~K}_{\mathrm{a}}$-band radar interferometry to measure surface water levels to $10 \mathrm{~cm}$ accuracy on smaller rivers

$63 \sim 100 \mathrm{~m}$ wide such as are found in the UK when in flood (Biancamaria et al. 2010). Assimilation

64 of simulated SWOT water levels into hydraulic models has been considered by Andreadis et al.

65 (2007) and Biancamaria et al. (2011). As SWOT is not scheduled for launch until 2020 and will

66 not measure levels for floods less than $100 \mathrm{~m}$ wide, the water levels from SAR flood boundaries

67 should continue to be an important source of data for assimilation into models, especially in the

68 near future. It is worth noting that the water levels used in conjunction with the hydraulic

69 model/assimilation system provide an indirect method of measuring river discharge from space.

71 Although models run in hindcasting mode can provide useful information for minimising the

72 effects of future floods, the ultimate goal must be to use SAR water levels in a forecasting

73 model, which means that they have to be estimated in near real-time. It might be questioned

74 whether it is possible, having acquired a raw SAR image, to perform the processing required to

75 extract a set of water levels in near real-time, given the substantial number of tasks involved. It is

76 necessary to download the image to the ground station, process the raw SAR data to a multi-look 
77 SAR image, perform automatic geo-registration using the spacecraft orbit parameters, extract the

78 flood extent from the image automatically, and select a distributed subset of water levels for

79 assimilation. It appears that there are reasons for optimism on this front. ESA has already

80 developed the FAIRE system for ASAR data, which while Envisat was functioning was able to

81 provide processed geo-registered ASAR images only 3 hours after acquisition of the raw data

82 (Cossu et al. 2009). While such systems still have to be developed for newer high resolution

83 SARs such as TerraSAR-X and COSMO-SkyMed, they do at least appear technically feasible. In

84 addition, algorithms have been developed for extracting a flood extent from a SAR image

85 automatically and in near real-time, for flooding in rural areas by Martinis et al. (2009, 2011),

86 and in both urban and rural areas by Mason et al. (2012).

87

88 It would be useful to complete the chain of automation by developing an automatic near real-

89 time method of selecting a subset of water levels from a SAR flood extent (Schumann et al.

90 2011). Assimilation techniques such as the Ensemble Kalman Filter (EnKF) assimilate water

91 levels from a subset of points along a flood extent by generating an ensemble of model runs in

92 which the levels are varied about their observed values by an amount governed by their variance.

93 It is necessary to select a subset of levels because adjacent levels along the flood extent will be

94 strongly correlated and add little new information, while a large number of levels will increase

95 the computational cost unnecessarily. The subset of points selected should be at positions at

96 which the water level can be accurately determined, with the points distributed uniformly over

97 the flood extent, sufficiently sparsely that adjacent water levels are spatially uncorrelated. This

98 could be viewed as an extension of an automatic near real-time algorithm for SAR flood extent

99 delineation. Without such an algorithm, it is not possible to perform near real-time assimilation 
of SAR-derived flood water levels into a flood forecasting model. The objective of this paper is to develop and test a suitable algorithm satisfying the above requirements.

\section{Study area and data set}

In common with a number of previous studies, the data set used for this study was acquired during the 1-in-150-year flood that took place on the lower Severn around Tewkesbury, U.K., in July 2007 (Mason et al. 2010, Schumann et al. 2011). This resulted in substantial flooding of urban and rural areas, about 1500 homes in Tewkesbury being flooded. Tewkesbury lies at the confluence of the Severn, flowing in from the northwest, and the Avon, flowing in from the northeast. The peak of the flood occurred on July 22 , and the river did not return to bank-full until July 31. On July 25, TerraSAR-X acquired a 3m-resolution StripMap image of the region (Fig.1), showing considerable detail in the flooded urban areas (Fig. 2). The TerraSAR-X incidence angle was $24^{\circ}$, and the image was $\mathrm{HH}$ polarisation multi-look ground range spatially enhanced. At the time of overpass, there was relatively low wind speed and no rain. Aerial photos of the flooding were acquired on July 24 and 27, and these were combined to validate the flood extent and candidate water level points extracted from the TerraSAR-X image (Mason et al. 2010). The data set also included airborne scanning laser altimetry (LiDAR) data ( $2 \mathrm{~m}$ resolution, $0.1 \mathrm{~m}$ height accuracy) of the un-flooded area, with coincident LiDAR and aerial photography covering the two regions identified in Fig. 1. Rectangular region A covers the Tewkesbury urban area (2.6 x 2km) (Fig. 2), while region B covers a larger more rural area along the Severn (with north-south extent $12.3 \mathrm{~km}$, east-west extent $6 \mathrm{~km}$ ). The TerraSAR-X and LiDAR data in region A were re-sampled to $1 \mathrm{~m}$ pixel size to maintain resolution in the urban 
122 flood detection procedure (Mason et al. 2012), while the data in region B were sampled at a 123 lower resolution (2.5m pixel size).

\section{3. Flood extent extraction algorithm}

126 The input to the method for selecting a subset of candidate water levels is a flood extent

127 extracted from a high resolution SAR image. Although it would be possible to detect candidate

128 waterline points in the image directly, there are significant advantages in selecting these from the 129 waterline of a flood extent extracted using a sophisticated algorithm based on object

130 segmentation and classification, which takes into account, for example, object heights as well as

131 SAR backscatter, and the presence of radar shadow and layover in urban areas. Previous work

132 has involved the development of such an algorithm for the extraction of flood extent in both

133 urban and rural areas from a high resolution SAR image automatically and in near real-time. This

134 is described in (Mason et al. 2012) and only a summary is given here.

136 The algorithm first detects the flood in the rural areas. Instead of using per-pixel classification,

137 the image is segmented into homogeneous regions, which are then classified on the basis of their

138 spectral, textural, shape and contextual features. Classification is performed by assigning all

139 segmented regions with mean SAR backscatter less than a threshold to the 'flood' class. To

140 determine the threshold, training regions for 'flood' are automatically selected from regions

141 giving no return in the LiDAR data (i.e. water that has acted as a specular reflector), and for

142 'non-flood' from un-shadowed areas well above the flood level. The initial segmentation is

143 refined using a variety of rules e.g. flood regions having mean heights significantly above the

144 local flood height are reclassified as non-flood. 
146 A simpler region-growing technique is used in the urban areas, guided by knowledge of the local

147 waterline heights in adjacent rural areas. A SAR simulator is used in conjunction with LiDAR

148 data to estimate regions of the image in which water would not be visible due to shadow or

149 layover caused by buildings and taller vegetation. A set of seed pixels having backscatter less

150 than the threshold, and heights less than or similar to the adjacent rural waterline heights, is

151 identified. Seed pixels are clustered together provided that they are close to other seeds. Regions

152 of shadow and layover are masked out in the processing.

153

154 The algorithm was developed using the TerraSAR-X image and associated data acquired for the

155 Tewkesbury 2007 flood. The algorithm proved capable of detecting flooding in rural areas using

156 TerraSAR-X with good accuracy, classifying $89 \%$ of flooded pixels correctly, with an associated

157 false positive rate of $6 \%$. Of the urban water pixels visible to TerraSAR-X, $75 \%$ were correctly

158 detected, with a false positive rate of $24 \%$. Fig. 3 shows the flood extents extracted in urban and

159 rural areas.

160

161 4. Method of candidate water level selection

1624 .1. Overview

163 The method consists of five stages, as shown in Fig. 4 :

165 (a) Candidate waterline point selection in rural areas.

166 (b) Correction of rural waterline positions and levels due to the presence of emergent 167 vegetation at the flood edge. 
(c) Candidate waterline point selection in urban areas.

(d) Candidate point thinning to reduce spatial autocorrelation, using a top-down clustering approach.

(e) Estimation of spatial autocorrelation, possibly involving repeating step (d) with different clustering thresholds until the remaining candidate water levels are uncorrelated.

Table 1 gives the input and output images, optimum parameter values and acceptable parameter ranges for the stages shown in Fig. 4.

This method is aimed at providing input to an assimilation system in which a single set of candidate waterline positions is identified, prior to performing an ensemble of model-forecastassimilation runs by varying the water levels at these points about their observed values by amounts governed by the level variance. This method is employed because there are usually fixed measurement positions along the reach (e.g. at gauges), but this is not so if a flood extent is available. An alternative in this case might be to select random subsets of candidates from the flood extent waterline, which would vary in position, only retain those subsets in which the errors on the levels within the subset were uncorrelated (Stephens et al. 2012), then perform an ensemble of model-forecast-assimilation runs using the observed water levels directly, which would contain the level errors. A difficulty with this approach is that, while the errors on each subset of levels would be uncorrelated within a subset, the errors on different subsets might be correlated with each other and might not be independent. 


\subsection{Candidate waterline point selection in rural areas.}

191 Candidate waterline points are first selected from the flood extent in rural areas. Sections of 192 waterline in the interior of the flood extent caused by regions of emergent vegetation (e.g. 193 hedges) may have erroneously low water levels associated with them. While most of these will

194 have been removed at the segmentation stage, residual sections must be removed prior to further 195 processing. As such sections bound regions that are often thin, they can generally be removed by

196 performing a dilation and erosion operation on the binary flood extent, whereby the extent is first 197 dilated by $30 \mathrm{~m}$, then eroded by the same amount. Waterline pixels are detected by applying a 198 Sobel edge detector (Castleman 1996) to the modified flood extent, and retaining only the 199 external edge pixels. It is required that an edge pixel is present at the same location before and 200 after dilation and erosion, in order to select for true waterline segments on straighter sections of 201 exterior boundaries in the flood extent. Fig. 6a shows candidate waterline points remaining after 202 the dilation/erosion operation in a small test area of region B.

204 To cope with the fact that candidate water levels will invariably exhibit a trend down the reach, 205 the reach is divided up into sub-areas of a few $\mathrm{km}$ length. Within each sub-area, false positives 206 are further suppressed by selecting waterline points in regions of low DEM slope within a certain 207 height range centred on the mean water height in the sub-area. A waterline point may be 208 heighted more accurately if it lies on a low slope rather than a high slope because any error in its 209 position will cause only a small error in height. The slope threshold must be set quite high (0.25), 210 because in a valley-filling event the waterlines may be on moderate rather than shallow slopes. In 211 addition, selected points must be more than 30m away from any pixel with slope higher than the 
212 slope threshold, to avoid selecting points in areas of radar shadow caused by taller vegetation or

213 buildings.

215 In order to find the allowed waterline level range in a sub-area, a histogram is constructed of the

216 waterline levels, and the positions of the histogram maxima are found, including that of the

217 largest maximum. Generally, the representative waterline level in the sub-area is set to

218 correspond to the level of the largest maximum. However, if any substantial maxima greater than

219 half that of the largest maximum is present at a higher level, the highest of these is chosen

220 instead. This latter rule copes with the situation where a substantial number of erroneous low

221 waterline levels in the interior of the flood extent have not been eliminated. A normal

222 distribution $N(\mu, \sigma)$ is fitted around the maximum $\mu$, with the standard deviation $\sigma$ estimated

223 from the histogram frequencies above $\mu$. Candidate waterline points with levels more than $2.5 \sigma$

224 away from $\mu$ are suppressed. Fig. 5 shows the histogram for sub-area covering the northern half

225 of region B, together with the upper and lower bounds of the allowed candidate level range. Fig.

226 6b shows candidate waterline points selected from a second small test area of rural region B at

227 the end of this stage.

228

229 4.3. Correction of rural waterline positions and levels due to the presence of emergent 230 vegetation at the flood edge.

231 While the candidate waterline points selected in rural areas will be in regions of low slope and

232 short vegetation, there will generally still be some vegetation present at the flood edge. This may

233 cause increased backscatter compared to that from a smooth open water surface due to double

234 reflection between the water surface and any emergent vegetation. Bright returns from flooded 
235

236

237

238

239

240

241

242

243

244

245

246

247

248

249

250

251

252

253 254 containing gauges.

255

256

257

marshland using X-band SAR have been observed by Ormsby et al. (1985), though they observed no backscatter enhancement in forests, probably due to low canopy penetration. At longer wavelengths (C- and L-band), enhanced backscatter has also been observed in inter-tidal marshland by Horritt et al. (2003) and Ramsay (1995), and at forest edges by Hess et al (1990). Horritt et al. (2003) reviews the substantial literature on this topic, and considers how double reflection may change the water level at the flood edge as well as the flood extent. The current flood extraction algorithm searches for regions of low backscatter less than a threshold, and Fig. 7 illustrates how this may cause an underestimation of the true flood extent and also of the flood level, as the waterline of the reduced extent may intersect the floodplain DEM at a lower level.

LiDAR has been used to map short vegetation heights (Cobby et al. 2001, Weltz et al. 1994), and these heights can be used to correct the estimated waterline levels by adding the height of the vegetation at the waterline. This information, together with knowledge of the local slope, also enables a corrected waterline position to be estimated. However, the LiDAR data will have been obtained over the un-flooded reach, perhaps at a different time of year to the SAR image of the flood event, and the vegetation height might have been different at the different times. An alternative approach might be to correct the observed levels by calibrating them against those of nearby gauges, as there is unlikely to be a significant cross-transect level gradient between the gauge position and the flood edge. However, this method would not work for the many rivers not

The method of correction used here attempts to estimate a corrected waterline level and position directly from the SAR image. At each pixel on the flood edge, the direction perpendicular to the 
258 edge moving away from the flood is calculated using a 3 x 3-pixel Prewitt edge detector

259 (Castleman 1996). A transect of backscatter values is constructed along this direction, traversing

260 from inside the flood, across the waterline and across the region in which emergent vegetation

261 might be expected (Fig. 8). Each backscatter value along the transect is constructed by averaging

262 SAR backscatter values in a window 1 pixel long in the direction of the transect and 5 pixels

263 long perpendicular to it centred on the transect. The minimum backscatter $\left(\min _{f}\right)$ in the flood

264 region between transect positions $O$ (within the flood) and $d l$ (at the waterline) is found. The

265 position (maxpos) of the first maximum in the backscatter values moving from $d 1$ to $d 2$ (the

266 transect position furthest into dry vegetation) is also calculated. The first point of maximum

267 positive curvature (maxpcurv) greater than a threshold (pcurv_thresh) moving from maxpos to $d 2$

268 is taken as the corrected position of the waterline for this transect. However, if the height at

269 maxpcurv is not significantly higher (by $0.1 \mathrm{~m}$ or more) than the height at the position of

270 minimum SAR backscatter $\min _{f}$, the waterline point is aborted as the transect may lie across an

271 artefact such as a flooded hedge. In the event that no point of maximum positive curvature is

272 found, it is assumed that no enhanced backscatter due to vegetation affects this waterline point,

273 and its original position is retained. While the procedure corrects the waterline position and level,

274 the uncertainty in determining the true waterline position introduces additional noise into the

275 estimates. This is due to the fact that the position of the true waterline, lying between emergent

276 and dry vegetation, is inherently more uncertain than the position of the uncorrected waterline at

277 the junction of open water and emergent vegetation, as there is generally a larger change in

278 backscatter across the latter junction (see Fig. 8). Fig. 6b shows corrected candidate waterline

279 point positions after this stage in the second test area of rural region B. 


\subsection{Candidate waterline point selection in urban areas.}

282 Although the vast majority of a flooded area may be rural rather than urban, it is very important 283 to detect candidate points in urban areas because of the higher risks and costs associated with 284 urban flooding. The level observations in urban areas can be assimilated into urban flood models 285 to improve their estimated levels.

287 The flood extent extraction algorithm ensures that urban flood pixels must be outside regions of 288 radar shadow and layover. They must also have heights less than the spatially-varying flood 289 height threshold that is applied in urban areas, based on flood heights in the adjacent rural areas. 290 This height threshold is set sufficiently high above the adjacent rural flood height that the heights 291 of urban flood waterline pixels can be regarded as independent of those in the adjacent rural 292 areas. The aim of this step is to select candidate waterline pixels that are less likely to be 293 influenced by the nearby presence of radar shadow and layover, and by the spatially-varying 294 height threshold, and are consequently more likely to be accurately heighted. The input to the 295 step is the flood extent in the urban area. Because urban flood pixels are likely to be few in 296 number compared to rural ones, a specific slope threshold is not applied.

298 The method uses a weighted distance-with-destination transform (see e.g. Mason et al. 2006). In 299 the normal Euclidean distance transform (Castleman 1996) each non-flood pixel's value is the 300 Euclidean distance to the nearest flood pixel, with the distances at flood pixels being set to zero. 301 To approximate a Euclidean distance, distance increments of 2 and 3 are used between adjacent 302 pixels in the axial and diagonal directions, respectively. The distance-with-destination transform 303 is a form of distance transform that stores for each non-flood pixel its distance to the nearest 
304 flood pixel, and also the direction from which the minimum distance was propagated. This

305 allows back-tracking from a non-flood pixel to find its nearest flood pixel. In the weighted

306 distance-with-destination transform, assuming logical $h \_d i s t$ is TRUE if pixel $(i, j)$ is not in a

307 shadow/layover region and not above the spatially-varying flood height threshold, the distance

308 increments are weighted by a function $w(h)$ of the form -

309

310

311

312

313

314

315

316

317

318

319

320

321

322

323

324

325

326

$$
\begin{array}{rlrl}
w(h) & =1 & & \text { if } h \_d i s t \text { is TRUE } \\
& =|h(i, j)-h(i+x, j+y)| & \text { otherwise }
\end{array}
$$

where $(i+x, j+y)$ is the neighbour adjacent to $(i, j)$ (with $-1 \leq x \leq 1,-1 \leq y \leq 1)$ for which the distance increment is minimum and $h(i, j)$ is the height at $(i, j)$. For pixels not in shadow or layover regions and below the urban flood height threshold, their distance increments are weighted to be simply the geometric increments, whereas other pixels have larger weights multiplying their geometric increments depending on the height differences at adjacent pixels.

A set of urban flood waterline pixels is chosen using the weighted and unweighted distance transforms. For an urban non-flood pixel at a certain threshold distance $d$ thresh from its nearest urban flood pixel, its associated weighted distance is found. If its normalised distance (i.e. weighted distance/unweighted distance) is less than a threshold $d \_$norm $(>1)$, the weighted distance-with-destination transform is used to track back to find the flood waterline pixel associated with this non-flood pixel. This urban flood waterline pixel is then selected as a candidate for further processing. Fig. 9 shows candidate waterline points selected in a small test urban area of rectangle A. 


\subsection{Candidate waterline point thinning.}

328 At this stage in the processing of the flood extent, there will generally be a large number of 329 candidate points remaining in both rural and urban areas. These will often be clustered together 330 so that their levels will be strongly spatially correlated with adjacent points adding little new 331 information, in addition to being so numerous as to increase the computational cost of the 332 assimilation unnecessarily. To ameliorate this problem, an adaptive thinning algorithm due to 333 Ochotta et al. (2005) is applied to the candidates in both rural and urban areas to reduce their 334 number while retaining their essential information content. The method adopts a top-down 335 clustering approach using a distance metric that combines spatial distance with difference in 336 observation values. Observations with similar spatial positions and water levels are grouped into 337 clusters which are approximated by one representative measure (i.e. the mean of the cluster).

339 The method begins by approximating the full dataset $P_{0}$ by the cluster mean with respect to a 340 distance measure. Specifically, the dataset is considered as a cluster $C$ with elements $p \in C, p=$

$341(x, y, z)^{T}$ that groups the observations at the positions $p$ with water levels $f(p)$. A distance metric $342 d_{f}(p, q)$ is defined that simultaneously takes into account the distances in space and water level 343 between two observations at positions $p$ and $q$ using the scaling factor $\alpha-$

$$
d_{f}(p, q)=\left(\|p-q\|^{2}+\alpha^{2}\|f(p)-f(q)\|^{2}\right)^{1 / 2}
$$

347 where $\|$ denotes the Euclidean metric. The cluster mean is defined as observation $\hat{p}$ that minimises the sum of squared distances to all cluster elements $q \in C$ - 


$$
e(C, p)=\sum_{q \in C} d_{f}(p, q)^{2}
$$

$$
\hat{p}=\arg \min _{p \in C} e(C, p)
$$

$353 e(C)=e(C, \hat{p})$ is taken as the cluster error, and is an estimate of the approximation quality of $\mathrm{C}$.

354 Initially all observations are taken to be in one cluster, so that $C_{0}:=P_{0}$ and $U:=\left\{C_{0}\right\}$ (Fig.

$35510(\mathrm{a}))$. In the splitting phase, any cluster $C \in U$ with an error $e(C)$ that is larger than a given 356 threshold $t>0$ is subdivided. Principal Component Analysis is used to split $C$ across its major 357 principal axis through the cluster centroid (Fig. 10b) (see Ochotta et al. 2005). The process of 358 cluster splitting is continued until all clusters in $C \in U$ satisfy $e(C) \leq t$ (Fig. 10c). The clustering phase of the algorithm is followed by a relaxation phase, which may reduce the total approximation error further. Each cluster element $p \in C_{i}$ is reassigned to the cluster $C_{j}$ for which the distance to the cluster mean is minimum with respect to $d_{f}$. This may change the means for affected clusters and require their recomputation. This process is repeated until

364 convergence. The cluster centroids $\hat{p}_{i}$ in the thinned dataset $P_{i}$ are used to represent the original 365 observations $p \in P_{0}$. The errors on the centroid water levels should be smaller than those on the original observations, and should tend towards the errors on the cluster means. Fig. $6 \mathrm{~b}$ shows the 367 candidate waterline point remaining after thinning in the second test area of rural region B. 


\subsection{Estimation of spatial autocorrelation.}

372 The errors on the resulting set of candidate water levels should be spatially uncorrelated, so that

373 the observation error covariance matrix used in the subsequent assimilation procedure can be 374 treated as diagonal. The spatial autocorrelation of a set of features can be measured using

375 Moran's I test, which measures spatial autocorrelation based on both feature values and feature

376 locations simultaneously (Moran 1950). The feature values (water levels) used in the test will be

377 the means of the values used to generate the ensemble employed in the assimilation. Even so, the

378 spatial autocorrelation obtained using the mean values should be a good indication of the spatial 379 autocorrelations of the individual ensemble members, as the feature locations would remain the 380 same.

381 Moran's I is defined as

$$
I=\frac{N}{\sum_{i} \sum_{j} w_{i j}} \frac{\sum_{i} \sum_{j} w_{i j}\left(X_{i}-\bar{X}\right)\left(X_{j}-\bar{X}\right)}{\sum_{i}\left(X_{i}-\bar{X}\right)^{2}}
$$

where $N$ is the number of spatial units (i.e. candidate points) indexed by $i$ and $j, X$ is the variable

384 of interest (in this case water level), $\bar{X}$ is the mean of $X$, and $w_{i j}$ is an element of a matrix of

385 spatial weights. The weights $w_{i j}\left(0<w_{i j}<1\right)$ take values that are high for neighbours that are 386 close, and low for neighbours far apart. In this case, $w_{i j}$ was set to be the inverse distance 387 between candidate points $i$ and $j$. Weights $w_{i i}$ are set to zero. Moran's I values range from -1 388 (perfect dispersion) to +1 (perfect correlation), with values of 0 for a random spatial pattern. For 389 statistical hypothesis testing, these values can be converted to a $\mathrm{Z}$ score, where $-1.96<\mathrm{Z}<1.96$ 390 represents candidate sets with no spatial autocorrelation (dispersion or correlation) at the 5\% 
391 significance level. Moran's I has been used to measure spatial autocorrelation in the errors on

392 water levels derived from SAR flood extents previously by Stephens et al (2012).

393 The candidate water levels will invariably exhibit a drift to lower values travelling down the

394 modelled reach, and there may also be cross-reach drift. As with variogram construction in the

395 presence of drift, it is necessary to remove the drift component from the levels before estimating

396 their spatial autocorrelation. To effect the drift removal, a 2-D planar surface is fitted through the

397 candidate points, and the value $\left(X_{i}-\bar{X}\right)$ is the difference between the level at point $\mathrm{i}$ and the level

398 of the planar surface at that point. The variance of the resulting differences is an estimate of the

399 observation variance that may be used in the subsequent assimilation.

400

401 If the spatial autocorrelation is significant, the cluster threshold $t$ in the Ochotta method must be

402 raised and the thinning repeated for the higher value, in order to reduce the number of candidates

403 further. This process may be repeated until the candidate set remaining is uncorrelated.

404

405 5. Experiment results

406 The flood extents in regions A and B were processed through the five stages of the method.

407 Table 2 gives the number of candidate waterline points surviving after each stage.

408

409 Considering the initial candidate waterline point selection in rural areas (stage (a)), for rural

410 areas of region A, 114497 pixels were initially marked as being edge pixels in the flood extent.

411 After selection of those pixels on straighter external boundaries that were on low slopes, distant

412 from regions of high slope and within the required height range of the most frequent water level,

413845 pixels $(0.7 \%)$ remained. For rural region B, $3726(2.9 \%)$ of the initial 128848 edge pixels in 
414 the flood extent were selected for further processing. The higher initial edge density in region A

415 is a result of the higher image resolution used in region A.

416

417 We next consider the correction of rural waterline positions and levels due to the presence of

418 vegetation at the flood edge (stage (b)). For rural areas of region A, 606 pixels out of the 845

419 pixels input to this stage were successfully corrected (72\%), with pixels that could not be

420 corrected being ignored in the subsequent processing. The average increase in water level of the

421 corrected pixels was $0.31 \mathrm{~m}$, with a standard deviation on this increase of $0.25 \mathrm{~m}$, so that the

422 correction procedure introduced an additional noise component into the corrected water levels.

423 This reflects that fact that the position of the corrected waterline cannot be determined as

424 accurately as the position of the uncorrected waterline. For rural region B, 2937 pixels of the

4253726 pixels input to this stage were successfully corrected (79\%), though the average increase in

426 water level of the corrected pixels was higher at $0.48 \mathrm{~m}$, with a standard deviation on this increase

427 of $0.54 \mathrm{~m}$.

428

429 Candidate waterline point selection in urban areas (stage (c)) was applied only to the urban areas

430 of region A. The number of candidate urban flood waterline pixels subjected to the normalised

431 distance threshold test was 9943, and the number accepted, with distances below the threshold,

432 was $252(2.5 \%)$. A normalised distance threshold of 2.0 was applied.

434 In the candidate waterline point adaptive thinning stage (stage (d)), the scaling factor $\alpha$ scaling

435 the water level difference between two observations compared to their Euclidean separation

436 distance was set to 100. It was found that results were insensitive to the exact value of $\alpha$ over a 
437 range $10<\alpha<1000$. The cluster threshold $t$ was set to a lower value in region $\mathrm{A}$ than region $\mathrm{B}$,

438 so that more candidates could be obtained in the urban area and its rural surround than in the

439 largely rural area B. This made it easier to see spatial differences in water level in the urban area.

440 In region A, $t$ was set to $200 \mathrm{~m}$, and the observations in the rural area of A were thinned from an

441 initial number of 606 to a final number of $8(1.3 \%)$, while in the urban area observations were

442 thinned from 9943 to $4(0.04 \%)$. In rural region $\mathrm{B}, t$ was set to $500 \mathrm{~m}$, and observations were

443 thinned from 2937 to $11(0.4 \%)$. Fig. 11 shows the candidate waterline points remaining after

444 thinning in regions $\mathrm{A}$ and $\mathrm{B}$.

445

446 The spatial autocorrelation of the remaining candidate waterline points was calculated in stage

447 (e) using Moran's I test, for regions A and B separately and also combined (table 3). The Z

448 scores indicate that all three candidate sets were spatially uncorrelated at the 5\% significance

449 level. The standard deviations of the water level differences from the fitted 2-D planar surface

450 were $0.11 \mathrm{~m}$ for region $\mathrm{A}, 0.23 \mathrm{~m}$ for region $\mathrm{B}$, and $0.24 \mathrm{~m}$ for both regions combined. These

451 values indicate that the Ochotta top-down clustering thinning has reduced the uncertainties of the

452 water levels, which were increased by the correction of waterline positions and levels in stage

453 (b). An indication of the utility of the thinning stage can be obtained from the fact that, if the

454 spatial autocorrelation of the errors on the waterline level point set existing prior to thinning was

455 calculated for rural region $\mathrm{B}$, the $\mathrm{Z}$ score was extremely large, indicating high correlation among 456 the levels.

457

458 The spatial variation in waterline levels across a region can also be seen by examining the 2-D

459 planar surface fitted to the candidates in the region during the Moran's I test. In region B, the 
460 predominant slope $(-0.013)$ of the levels is in the direction of the river flow (almost N-S), while

461 the cross-river slope is only -0.003 . However, in region A, while there is still significant slope in

462 the N-S river flow direction (-0.026), there is also a significant W-E slope (-0.045), indicating

463 that levels in the East of Tewksbury were generally lower than those in the West, falling by

$464 \quad 0.45 \mathrm{~m}$ per $\mathrm{km}$ (see also Schumann et al. 2011). This information was extracted from the SAR-

465 derived waterline levels, and is not available from the local gauge levels.

466

467 Fig. 12 compares the candidate waterline point levels with the levels at gauges at Saxon's Lode

468 (386349E, 239041N) and Mythe Bridge (388899E, 233722N) in region B, at the time of the

469 TerraSAR-X overpass. The gauge levels are not dependent on the LiDAR DEM, so that the

470 gauges provide independent measurements of water level. From table 3, the standard deviation of

471 waterline point levels about the fitted planar surface is $0.23 \mathrm{~m}$. The trend of this surface is

472 predominantly in the N-S direction and is shown in Fig. 12. From modelling results, no

473 significant difference should be expected between the water level at the gauge position near the

474 centre of the river and the level of the waterline at the same distance downstream. For both

475 gauges, the difference in level from the trend surface is less than one standard deviation, so that

476 no significant bias between the SAR-derived and gauge levels could be detected.

477

478 We also investigated whether the candidate waterline points selected automatically appeared to

479 be at the correct position and level by manual inspection of aerial photographs. The aerial photos

480 were not exactly contemporaneous with the TerraSAR-X overpass on $25^{\text {th }}$ July, as those of $24^{\text {th }}$

481 July were acquired about 19 hours before the overpass and those of $27^{\text {th }}$ July about 53 hours after

482 it. It was established that the gauge level changed almost linearly over this 72-hour period, so 
483 that by estimating the position and level of a particular waterline point in the two sets of aerial

484 photos, its position and level at TerraSAR-X overpass time could be estimated for comparison

485 with the SAR-derived values. A set of 9 candidate waterline points selected by the Ochotta

486 method in region B were identified, which were also visible in both sets of aerial photos. The

487 waterlines in the aerial photos appeared quite sharply defined, so that it was possible to estimate

488 their positions to within about 2 pixels. The aerial photo waterline levels in the set proved to be

489 slightly but significantly lower $(0.14 \pm 0.11 \mathrm{~m})$ than those derived from the TerraSAR-X image,

490 which were shown above to be not significantly different from the gauge levels. Part of the

491 reason for this difference may be that a slight underestimation of the true waterline may be being

492 made in the aerial photos, perhaps due to the presence of vegetation. To test this, the levels of

493 waterline positions on roads visible in the aerial photos were compared to the levels in fields

494 adjacent to the roads, on the basis that roads would be unvegetated areas. Based on a set of 6

495 measurement pairs, it was found that the levels on the roads exceeded those on the adjacent

496 fields by $0.20 \pm 0.36 \mathrm{~m}$, though the difference was not significantly non-zero. The large spread on

497 the differences was partly due to the fact that the measurements could not always be made on

498 low slopes because of the paucity of flooded roads in region B.

499

500 6. Discussion and Conclusions

501 A method for selecting a subset of high resolution SAR waterline levels for assimilation into a

502 hydraulic model has been developed. This is automatic and near real-time to allow the levels to

503 be used in a forecasting mode. The method selects candidate waterline points in flooded rural

504 areas having low slope, and corrects their levels and positions for the effects of double

505 reflections between the water surface and emergent vegetation at the flood edge. Waterline 
506 points with levels similar to those in adjacent rural areas are also selected in flooded urban areas

507 away from radar shadow and layover. The resulting points are thinned to reduce spatial

508 autocorrelation using a top-down clustering approach. The waterline points extracted from a

509 TerraSAR-X image containing urban and rural flooding proved to be spatially uncorrelated, with

510 levels reasonably similar to those determined from contemporaneous aerial photos. They were

511 also in good agreement with those of nearby gauges, and sufficiently accurate to be useful in any

512 subsequent assimilation procedure.

514 The method of subset selection is based on the twin premises that it is necessary to select a

515 subset of levels because adjacent levels along the flood extent will be strongly correlated and add

516 little new information, and that a large number of levels will increase the computational cost of

517 assimilation unnecessarily. Even so, at this stage the impact that the data reduction may have on

518 a subsequent assimilation stage remains unclear. This might depend on other factors in addition

519 to the number of observations and the spatial correlation of their errors, such as the complexity

520 of the hydrodynamic model and the type of filter used for assimilation. Further work is required

521 to investigate this aspect, by coupling the subset selection procedure with the assimilation stage

522 and investigating the information content and computation time associated with different subsets

523 of points obtained using different clustering thresholds, in order to try to find some optimum.

525 It should be borne in mind that the method presented has been developed using a TerraSAR-X

526 image of a single flood event. It would probably be incorrect to assume that the parameter set

527 optimised for this case study would necessarily be applicable to other flood events or SAR data

528 types. Further development of the method to extract level subsets for flood events on other types 
529 of reach using other types of SAR data is necessary before the method could be considered a

530 general one. While the method has been developed for high resolution SAR images, in principle

531 it should be applicable to lower resolution SAR images such as those obtained from Radarsat-1,

532 perhaps using a simpler automatic segmentation algorithm such as that described in Mason et al.

$533 \quad(2007$.

534

535 The TerraSAR-X image was acquired 3 days after the peak of the flood, when the flood was

536 entering its recessional phase. Fig. 11b shows a number of examples of levels selected along the

537 waterlines of water bodies not connected to the main channel. Assimilation of these levels into

538 the hydraulic model is helpful in allowing this to make an improved prediction of the rate of

539 floodplain dewatering. This is a further illustration of the additional information that can be

540 obtained from SAR-derived waterline levels compared to simply using levels from gauges.

541

542 The computing time required to perform the automatic waterline point selection for the larger

543 region $\mathrm{B}$ was a few minutes using IDL on a Sun SPARC station, with the dominant time being

544 the time to perform the adaptive top-down clustering. This time could be significantly reduced

545 using parallel processing However, it is important to stress that, in order to obtain a SAR flood

546 extent and a set of candidate waterline levels automatically and in near real-time, it is assumed

547 that a number of pre-processing operations will have been carried out in parallel with tasking the

548 satellite to acquire the image of flooding. These include procedures such as the generation of the

549 DEM and the delineation of the urban area, which could be performed offline at an earlier date

550 and retrieved between satellite tasking and image acquisition. The generation of the

551 shadow/layover map for the urban area by running a SAR simulator on the LiDAR data of the 
552 urban area, given the SAR trajectory and proposed look angle, could also be carried out during

553 this time. It is further assumed that download of the image to the ground station, processing of

554 the raw SAR to a multi-look image and automatic geo-registration using the spacecraft orbit

555 parameters could be carried out by a system analogous to ESA's FAIRE system, but one that

556 works in near real-time for newer high resolution SARs such as TerraSAR-X and COSMO-

557 SkyMed.

558

559 The method presented extracts a subset of candidate waterline levels automatically. It would

560 obviously be difficult to extract an equivalent subset of levels manually because of the

561 requirement that the levels should be extracted in near real-time to allow them to be used in a

562 forecasting mode. It is also likely that a manually-selected subset would be less accurate than one

563 determined automatically. The latter set would be corrected for the effects of double reflection

564 due to emergent vegetation using an objective algorithm, and the adaptive top-down clustering

565 would tend to reduce level errors by selecting waterline points whose levels were close to the

566 means of the clusters containing them.

567

568 Future work will concentrate on using the method as a pre-processor in the development of

569 techniques to assimilate SAR-derived waterline and gauge levels into coupled

570 hydrologic/hydraulic models in order to improve the model states and estimate model parameters

571 and external forcing. The method will also be tested under different conditions in order to assess

572 its generality, by extracting level subsets for flood events on other types of reach using other

573 types of SAR data, and assessing its sensitivity to the parameters given in table 1. 


\section{Acknowledgements}

576 This project was partly funded under the NERC Storm Risk Mitigation programme (grant no.

577 NE/I005242/1). The authors are grateful to the Environment Agency for provision of the LiDAR

578 data, and the NERC Flood Risk from Extreme Events (FREE) programme for funding the

579 acquisition of the aerial photos.

580

581 References

582 Alsdorf, D.E., Rodriguez, E., \& Lettenmaier, D.P. (2007). Measuring surface water from space.

583 Reviews of Geophysics, 45; doi:10.1029/2006RG000197.

584

585 Andreadis, K.M., Clark, E.A., Lettenmaier, D.P., \& Alsdorf, D.E. (2007). Prospects for river

586 discharge and depth estimation through assimilation of swath-altimetry into a raster-based

587 hydrodynamics model. Geophysical Research Letters, 34; doi:10.1029/2007GL029721.

588

589 Biancarmaria, S., Andreadis, K.M., Durand, M., Clark, E.A., Rodriguez, E., Mognard, M.N., 590 Alsdorf, D.E., Lettenmaier, D.P., \& Oudin, Y. (2010). Preliminary characterization of SWOT 591 hydrology error budget and global capabilities. IEEE JSTARS, 3(1), doi:

592 10/1109/JSTARS.2009.2034614.

593

594 Biancarmaria, S., Durand, M., Andreadis, K.M., Bates, P.D., Boone, A., Mognard, M.N., 595 Rodriguez, E., Alsdorf, D.E., Lettenmaier, D.P., \& Clark, E.A. (2011). Assimilation of virtual 596 wide swath altimetry to improve Artic river modeling. Remote Sensing of the Environment, $597 \quad 115(2), 373-381$. 
598 Castleman K.R. (1996). Digital image processing. New Jersey: Prentice Hall.

599

600 Cobby, D.M., Mason, D.C., \& Davenport, I.J. (2001). Image processing of airborne scanning

601 laser altimetry for improved river flood modelling. ISPRS J. Photogrammetry and Remote

602 Sensing, 56, 121-138.

603

604 Cossu, R.E., Schoepfer, P.B., \& Fusco, L. (2009). Near real-time SAR based processing to 605 support flood monitoring. J. Real-Time Image Processing, 4(3), pp. 205-218.

606

607 Frappart, F., Calmant, S., Cauhope, M., Seyler, F., \& Cazenave, A. (2006). Preliminary results of 608 ENVISAT RA-2-derived water levels validation over the Amazon basin. Remote Sensing of 609 Environment, 100, 252-264.

610

611 Giustarini, L., Matgen, P., Hostache, R.. \& Montanari, M. et al. (2011). Assimilating SAR-derived water 612 level data into a hydraulic model: a case study. Hydrology and Earth System Sciences, 15(7), 2349-2365.

613

614 Hess. L.L., Melack, J.M., \& Simonett, D.S. (1990). Radar detection of flooding beneath the forest canopy 615 - a review. Int. J. Remote Sensing, 11(7), 1313-1325.

616

617 Horritt, M.S., Mason, D.C., Cobby, D.M, Davenport, I.J., \& Bates, P.D. (2003). Waterline mapping in 618 flooded vegetation from airborne SAR imagery. Remote Sensing of the Environment 85, 271-281. 
620 Hostache, R., Matgen, P., Schumann, G., Puech, C., Hoffmann, L., \& Pfister, L. (2009). Water 621 level estimation and reduction of hydraulic model calibration uncertainties using satellite SAR 622 images of floods. IEEE Trans. Geosci. Remote Sens., 47, 431-441.

623

624 Lane, S.N., James, T.D., Pritchard, H., \& Saunders, M. (2003) Photogrammetric and laser 625 altimetric reconstruction of water levels for extreme flood event analysis. Photogrammetric 626 Record, 18, 293-307.

627

628 Lazarus, S.M., Splitt, M.E., Lueken, M.D., Ramachandran, R., Li, X., Movva, S., Graves, S.J., \& 629 Zovodsky, B.T. (2010). Evaluation of data reduction algorithms for real-time analysis. AMS 630 Weather and Forecasting, 25(3), 837-851.

631

632 Martinis, S., Twele, A., \& Voigt. S. (2009). Towards operational near real-time flood detection 633 using a split-based automatic thresholding procedure on high resolution TerraSAR-X data. 634 Natural Hazards and Earth System Sciences, 9, 303-314, .

635

636 Martinis, S., Twele, A., \& Voigt S. (2011). Unsupervised extraction of flood-induced backscatter 637 changes in SAR data using Markov image modeling on irregular graphs. IEEE. Trans. 638 Geoscience Rem. Sens., 49(1), 251-263.

639

640 Mason, D.C., Scott, T.R., \& Wang, H-J. (2006). Extraction of tidal channel networks from

641 airborne LiDAR data. ISPRS J. Photogrammetry and Remote Sensing, 61, 67-83. 
643 Mason, D.C., Horritt, M.S., Dall'Amico, J.T., Scott, T.R., \& Bates, P.D. (2007). Improving river

644 flood extent delineation from synthetic aperture radar using airborne laser altimetry. IEEE.

645 Trans. Geoscience Rem. Sens, 45(12), 3932-3943.

646

647 Mason, D.C., Speck, R., Devereux, B., Schumann, G.J-P., Neal, J.C., \& Bates, P.D. (2010).

648 Flood detection in urban areas using TerraSAR-X. IEEE. Trans. Geoscience Rem. Sens., 48(2), $649 \quad 882-894$.

650 Mason, D.C., Davenport. I.J., Neal, J.C., Schumann, G.J-P., \& Bates, P.D. (2012). Near real-time

651 flood detection in urban and rural areas using high resolution Synthetic Aperture Radar images.

652 IEEE. Trans. Geoscience Rem. Sens., 50(8). DOI: 10.1109/TGRS.2011.2178030

653

654 Matgen, P., Schumann, G., Henry, J., Hoffmann, L., \& Pfister, L. (2007) Integration of SAR-

655 derived inundation areas, high precision topographic data and a river flow model toward real-

656 time flood management. International Journal of Applied Earth Observation and

657 Geoinformation, 9, 247-263.

658

659 Matgen, P., Montanari, M., Hostache, R., Pfister, L., Hoffmann, L., Plaza, D., Pauwels, V. R. N.,

660 De Lannoy, G. J. M., De Keyser, R., \& Savenije, H. H. G. (2010). Towards the sequential

661 assimilation of SAR-derived water stages into hydraulic models using the Particle Filter: proof of 662 concept, Hydrol. Earth Syst. Sci., 14, 1773-1785.

663

664 Moran, P.A.P. (1950). Notes on continuous stochastic phenomena. Biometrika, 37(1/2), 17-23. 665 
666 Neal, J.C., Atkinson, P.M., \& Hutton, C.W. (2007). Flood inundation model updating using an 667 ensemble Kalman filter and spatially distributed measurements. Journal of Hydrology, 336, 401668415.

669

670 Neal, J.C., Schumann, G.J-P., Bates, P.D., \& Mason, D.C. (submitted). Estimating river

671 discharge with hydraulic models and remote sensing. J.Hydrology.

672

673 Ochotta, T., Gebhardt, C., Saupe, D., \& Wergen, W. (2005). Adaptive thinning of atmospheric

674 observations in data assimilation with vector quantization and filtering methods. Q.J.R.Met. Soc, $675131,3427-3427$.

676

677 Ormsby, J.P., Blanchard, B.J., \& Blanchard A.J. (1985). Detection of lowland flooding using 678 active microwave systems. Int. J. Remote Sensing, 5, 317-328.

679

680 Raclot, D. (2006). Remote sensing of water levels on floodplains: a spatial approach guided by 681 hydraulic functioning. International Journal of Remote Sensing, 27, 2553-2574.

682

683 Ramsay, E.W. (1995). Monitoring flooding in coastal wetlands by using radar imagery and 684 ground-based measurements. Int. J. Remote Sensing, 16, 2495-2502. 
686 Romanowicz, R.J., Young, P.C., \& Beven, K.J. (2006). Data assimilation and adaptive

687 forecasting of water levels in the river Severn catchment, United Kingdom. Water Resources

688 Research, 42(6), W06407.

689

690 Schumann, G. J-P., Matgen, P., Pappenberger, F. et al. (2007). High-resolution 3D flood

691 information from radar for effective flood hazard management. IEEE Trans. Geoscience and

692 Remote Sensing, 45, 1715-1725.

693

694 Schumann, G. J-P., Neal, J. C., Mason, D. C. \& Bates, P. D. (2011). The accuracy of sequential

695 aerial photography and SAR data for observing urban flood dynamics, a case study of the UK

696 summer 2007 floods. Remote Sensing of Environment, 115, 2536-2546.

697

698 Stephens, E., Bates, P.D., Freer, J., \& Mason, D.C. (2012). Calibration of flood inundation

699 models using uncertain satellite observed water levels. J. Hydrology, 414-415, 162-173.

700

701 Vorosmarty, C. J., Willmott, C. J., Choudhury, B. J., Schloss, A. L., Stearns, T. K., Robeson, S.

702 M. \& Dorman, T. J. (1996). Analyzing the discharge regime of a large tropical river through

703 remote sensing, ground-based climatic data, and modeling. Water Resources Research, 32, 3137-

7043150.

705 
706 Weltz, M.A., Ritchie, J.C., \& Fox, H.D. (1994). Comparison of laser and field measurements of 707 vegetation height and canopy cover. Water Resources Research, 30(5), 1311-1319. 


\begin{tabular}{|c|c|c|c|c|c|}
\hline Stage & Input images & Output image & Parameters & $\begin{array}{l}\text { Optimum } \\
\text { parameter } \\
\text { value }\end{array}$ & $\begin{array}{c}\text { Acceptable } \\
\text { parameter } \\
\text { range }\end{array}$ \\
\hline $\begin{array}{l}\text { (a) Waterline } \\
\text { point selection } \\
\text { in rural areas. }\end{array}$ & $\begin{array}{l}\text { 1. Rural flood } \\
\text { extent image } \\
\text { (binary). } \\
\text { 2. DEM. } \\
\text { 3. DEM slope } \\
\text { image. }\end{array}$ & $\begin{array}{l}\text { Candidate rural } \\
\text { water line levels. }\end{array}$ & $\begin{array}{l}\text { Dilation/erosion } \\
\text { distance. } \\
\text { Reach sub-area } \\
\text { length. } \\
\text { Slope threshold. } \\
\text { Distance from } \\
\text { high slope. }\end{array}$ & $\begin{array}{l}30 \mathrm{~m} \\
6 \mathrm{~km} \\
0.25 \\
30 \mathrm{~m}\end{array}$ & $\begin{array}{c}20-40 \mathrm{~m} \\
4-8 \mathrm{~km} \\
0.2-0.3 \\
25-35 \mathrm{~m}\end{array}$ \\
\hline $\begin{array}{l}\text { (b) Correction } \\
\text { of waterline } \\
\text { position/level } \\
\text { due to flood } \\
\text { edge vegetation. }\end{array}$ & $\begin{array}{l}\text { 1. Candidate } \\
\text { rural water line } \\
\text { levels. } \\
\text { 2. DEM. } \\
\text { 3. SAR image. }\end{array}$ & $\begin{array}{l}\text { Corrected } \\
\text { candidate rural } \\
\text { water line levels. }\end{array}$ & $\begin{array}{l}\text { Maximum } \\
\text { positive curvature } \\
\text { threshold } \\
\text { pcurv_thresh. } \\
\text { Height difference } \\
\text { between pixels at } \\
\text { maxpcurv and } \\
\text { min }_{f} \text {. }\end{array}$ & $\begin{array}{c}1 \mathrm{DN} / \mathrm{m}^{2} \\
0.1 \mathrm{~m}\end{array}$ & $\begin{array}{c}0.3-3 \mathrm{DN} / \mathrm{m}^{2} \\
0.05-0.15 \mathrm{~m}\end{array}$ \\
\hline $\begin{array}{l}\text { (c) Waterline } \\
\text { point selection } \\
\text { in urban areas. }\end{array}$ & $\begin{array}{l}\text { 1. Urban flood } \\
\text { extent image } \\
\text { (binary). } \\
\text { 2. Urban extent } \\
\text { image (binary). } \\
\text { 3. DEM. } \\
\text { 4. Shadow- } \\
\text { layover mask } \\
\text { (binary). } \\
\text { 5. Water height } \\
\text { threshold image } \\
\text { (binary). } \\
\text { 6. Corrected } \\
\text { candidate rural } \\
\text { water line levels. }\end{array}$ & $\begin{array}{l}\text { Corrected } \\
\text { candidate rural } \\
\text { and urban } \\
\text { waterline levels. }\end{array}$ & $\begin{array}{l}\text { Normalised } \\
\text { distance threshold } \\
\text { d_norm. }\end{array}$ & 2.0 & $1.5-2.5$ \\
\hline $\begin{array}{l}\text { (d) Waterline } \\
\text { point thinning. }\end{array}$ & $\begin{array}{l}\text { 1. Corrected } \\
\text { candidate rural } \\
\text { and urban } \\
\text { waterline levels. } \\
\text { 2. DEM. }\end{array}$ & $\begin{array}{l}\text { Thinned } \\
\text { corrected } \\
\text { candidate rural } \\
\text { and urban } \\
\text { waterline levels. }\end{array}$ & $\begin{array}{l}\text { Cluster distance } \\
\text { threshold } t \text {. } \\
\text { Scaling factor } \alpha \text {. }\end{array}$ & $\begin{array}{c}200 \mathrm{~m} \text { (urban), } \\
500 \mathrm{~m} \text { (rural). } \\
100\end{array}$ & $\begin{array}{c}\text { User-selectable. } \\
10-1000\end{array}$ \\
\hline
\end{tabular}


Table 2. Number of candidate waterline points surviving after each stage of reduction.

\begin{tabular}{|c|c|c|c|}
\hline Stage & Region A (rural) & Region A (urban) & Region B \\
\hline Input to (a) & 114497 & & 128848 \\
\hline After (a) & 845 & & 3726 \\
\hline After (b) & 606 & 9943 & \\
\hline Input to (c) & & 252 & \\
\hline After (c) & & 4 & 11 \\
\hline After (d) & 8 & & \\
\hline
\end{tabular}

\begin{tabular}{|c|c|c|c|}
\hline Variable & Region A & Region B & Combined regions \\
\hline No. of samples & 12 & 11 & 23 \\
\hline Moran's I value & -0.22 & -0.14 & -0.02 \\
\hline Z score & -1.39 & -0.33 & 0.34 \\
\hline Standard deviation of & 0.11 & 0.23 & \\
\hline water levels (m) & & & \\
\hline
\end{tabular}




\section{Figure captions}

721 1. TerraSAR-X image of the lower Severn/Avon July 2007 flood (dark areas are water) (C) DLR

722 2007). Rectangle A includes the urban area of Tewkesbury, and region B the rural validation 723 area.

724

725

2. TerraSAR-X image showing detail in the urban areas of Tewkesbury $(2.6 \times 2 \mathrm{~km})($ (C) DLR 726 2007).

727

728

3. Flood extents extracted in (a) rural area (blue = predicted flood, superimposed on TerraSAR-X 729 image), and (b) urban area (yellow = predicted flood, brown $=$ shadow/layover areas that may be

730 flooded, superimposed on LiDAR data) (after Mason et al. accepted).

731 4. Steps in the processing chain.

732

733 5. Histogram of candidate waterline levels for the northern half of region B (see Fig. 1). The 734 allowed candidate level range is $11.6 \mathrm{~m}-13.6 \mathrm{~m}$.

735

736

6. Test areas of rural region B showing (a) TerraSAR-X image, flood extent (blue) and candidate

737 waterline points selected after dilation and erosion in stage (a) (red); (b) TerraSAR-X image, 738 flood extent (blue), candidate waterline points selected at the end of stage (a) (green), corrected 739 candidate waterline point positions after stage (b) (magenta), and candidate waterline point 740 remaining after thinning in stage (d) (red).

741 
742 7. The effect of short vegetation on estimation of water surface elevations. The vegetation moves

743 the SAR waterline towards the flooding and the water level is underestimated (after Horritt et al.

744 2003).

745

746 8. Example transect of averaged SAR backscatter values across a flood edge into emergent

747 vegetation; (a) transect superimposed on SAR image; (b) SAR backscatter along transect. The

748 original waterline position $d 1$ is at pixel 6 . The transect position $d 2$ furthest into dry vegetation is

749 at pixel 16. The position of maximum positive curvature (maxpcurv) greater than the first

750 maximum (maxpos) after $d l$ is at pixel 12 . The height at pixel 12 is $11.93 \mathrm{~m}$, whereas that at $d l$ is

$751 \quad 11.43 m$.

752

753 9. Urban test area of rectangle A showing LiDAR image, urban flood extent (blue), candidate

754 waterline points selected in stage (c) (magenta), and candidate waterline point remaining after 755 thinning in stage (d) (red).

756

757 10. Concept of clustering method (after Ochotta et al. 2005). (a) Observations are grouped to a

758 cluster with a cluster centre (filled dot); (b) when the associated cluster error is too large, the

759 cluster is split by Principal Component Analysis, providing two new clusters; (c) this procedure

760 is repeated until all cluster errors are below a given threshold, $t>0$. The set of centroids is the

761 reduced observation set.

762 11. Candidate waterline points remaining after Ochotta clustering thinning in (a) region A and 763 (b) region $\mathrm{B}$. 
764 12. Water level versus position along northerly axis for candidate waterline points and gauges in 765 region $\mathrm{B}$. 


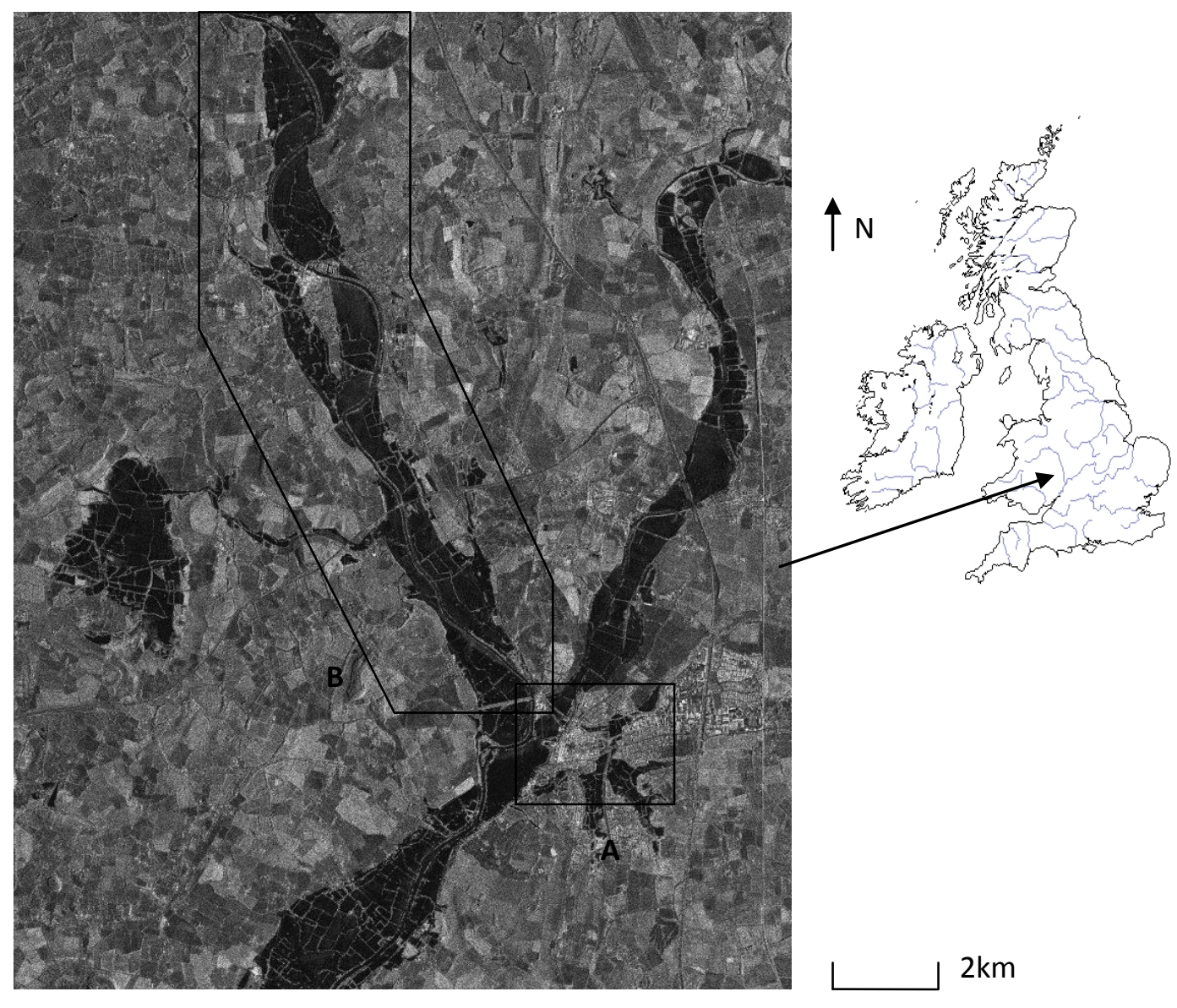

Figure 1. 


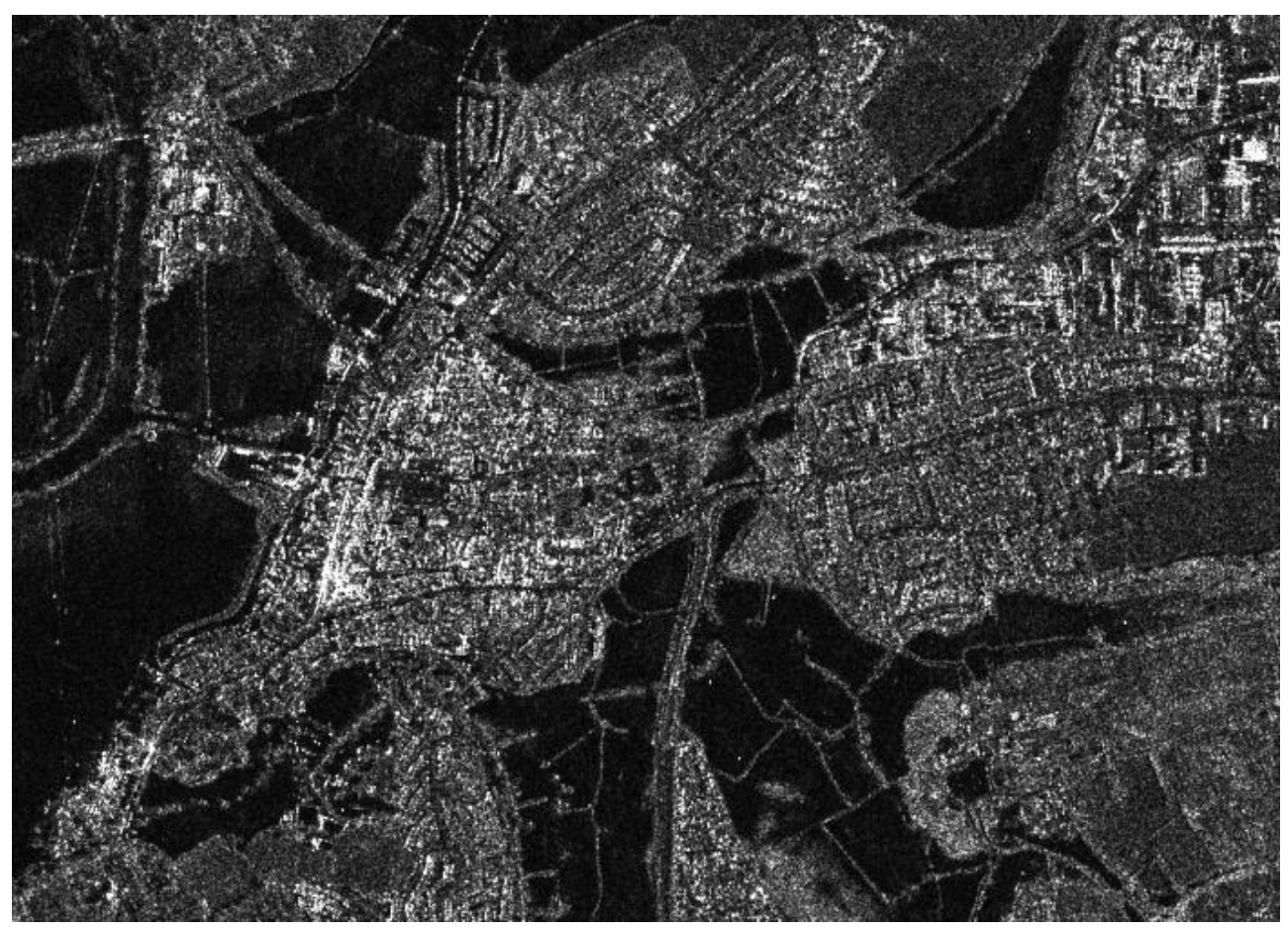

Figure 2. 


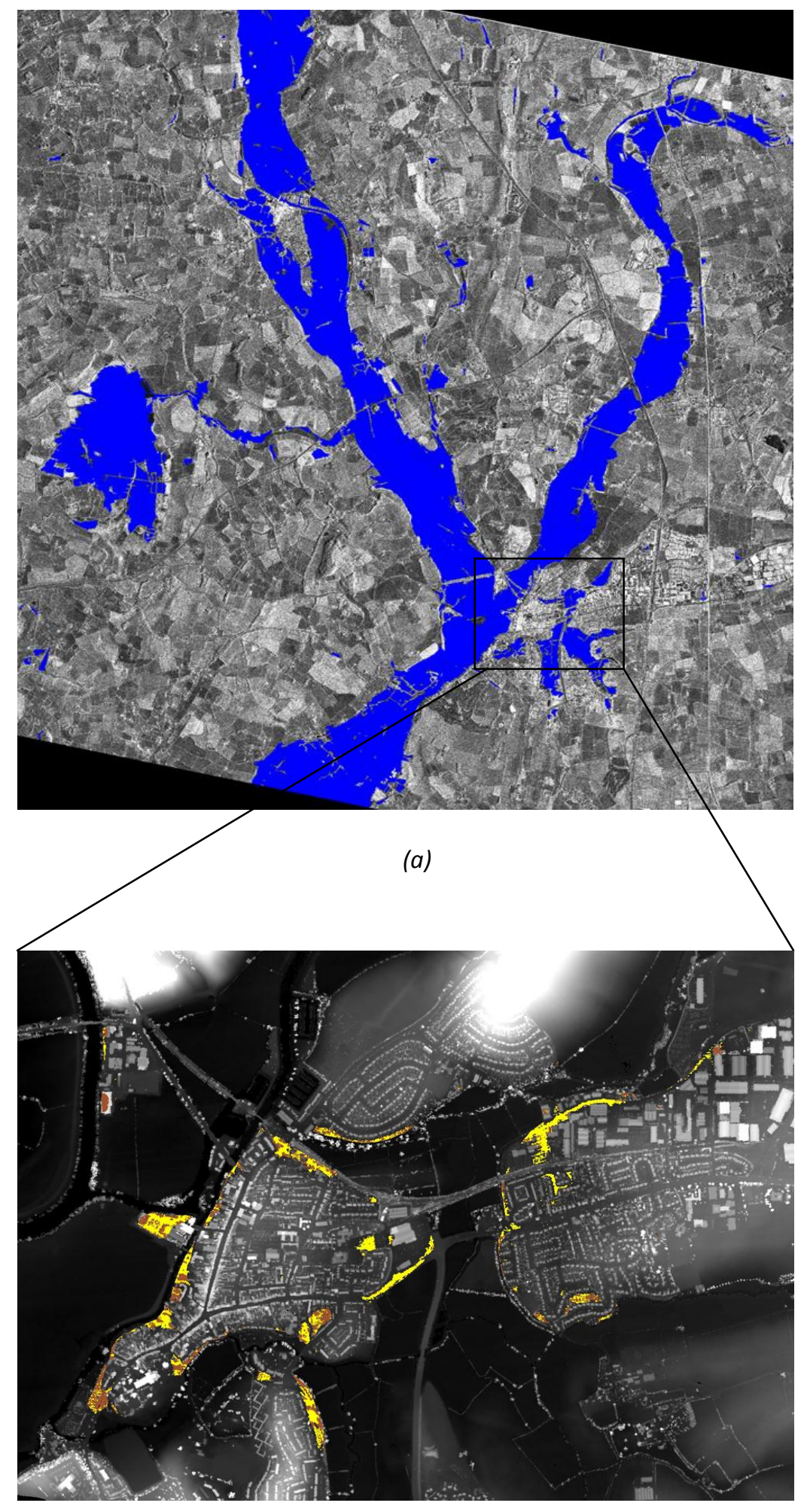

(b)

Figure 3. 


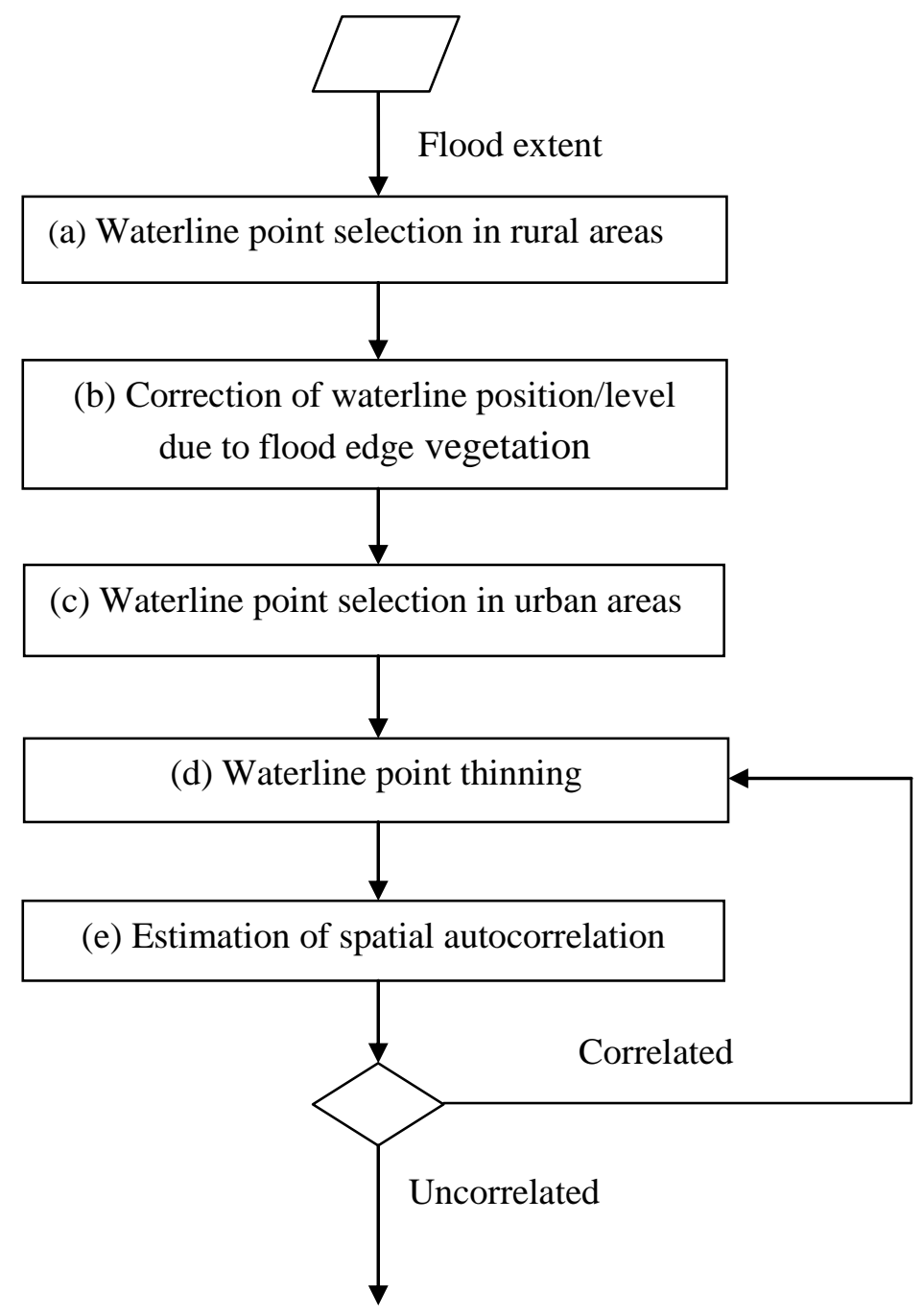

To assimilation

Figure 4. 


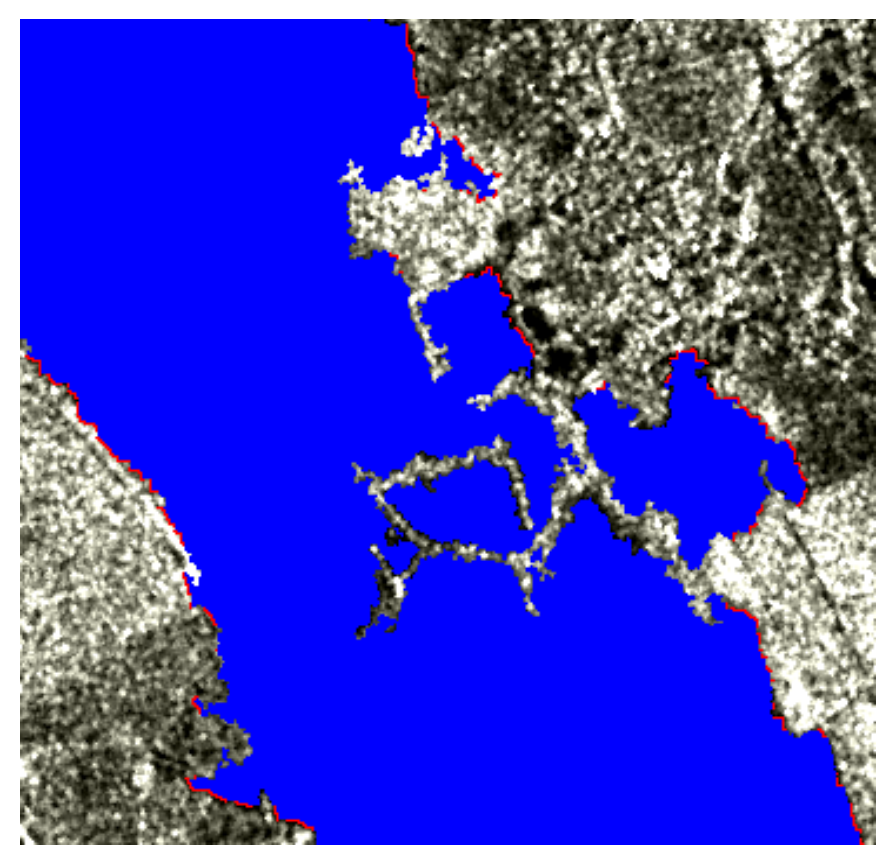

(a)

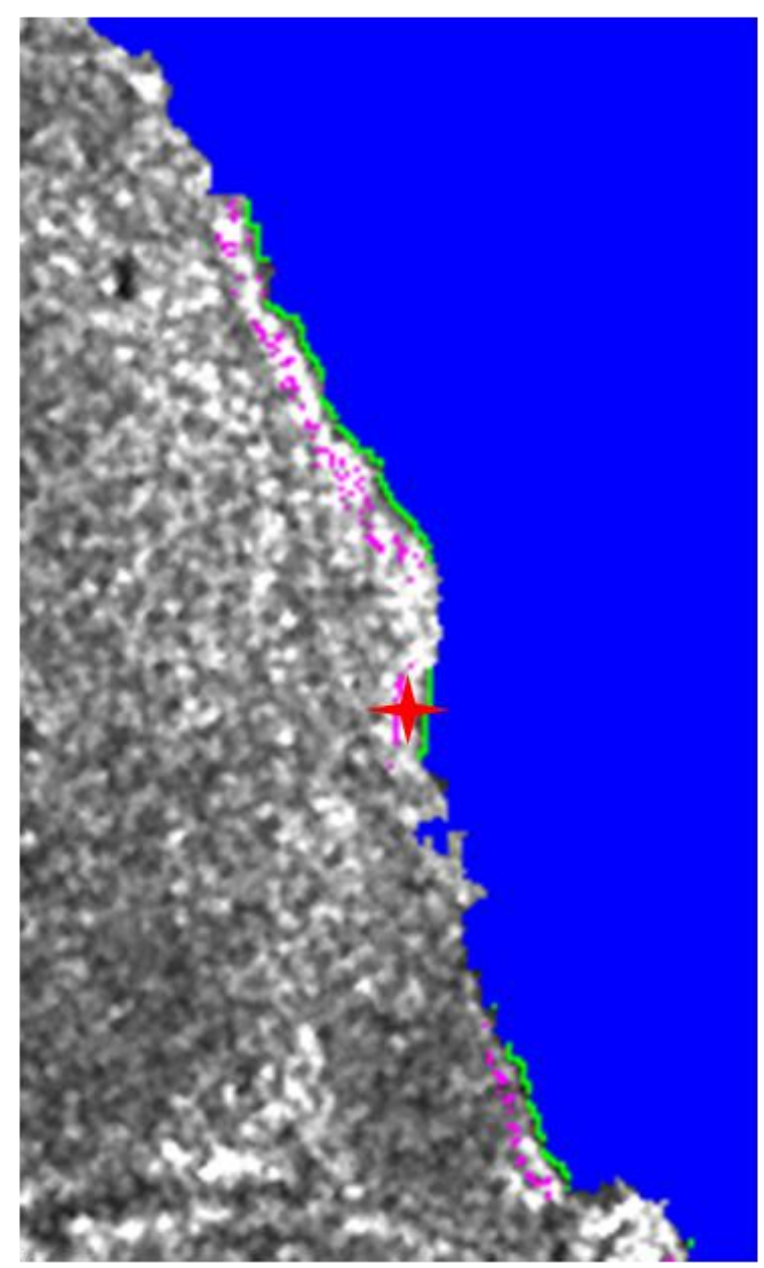

(b)

Figure 5. 


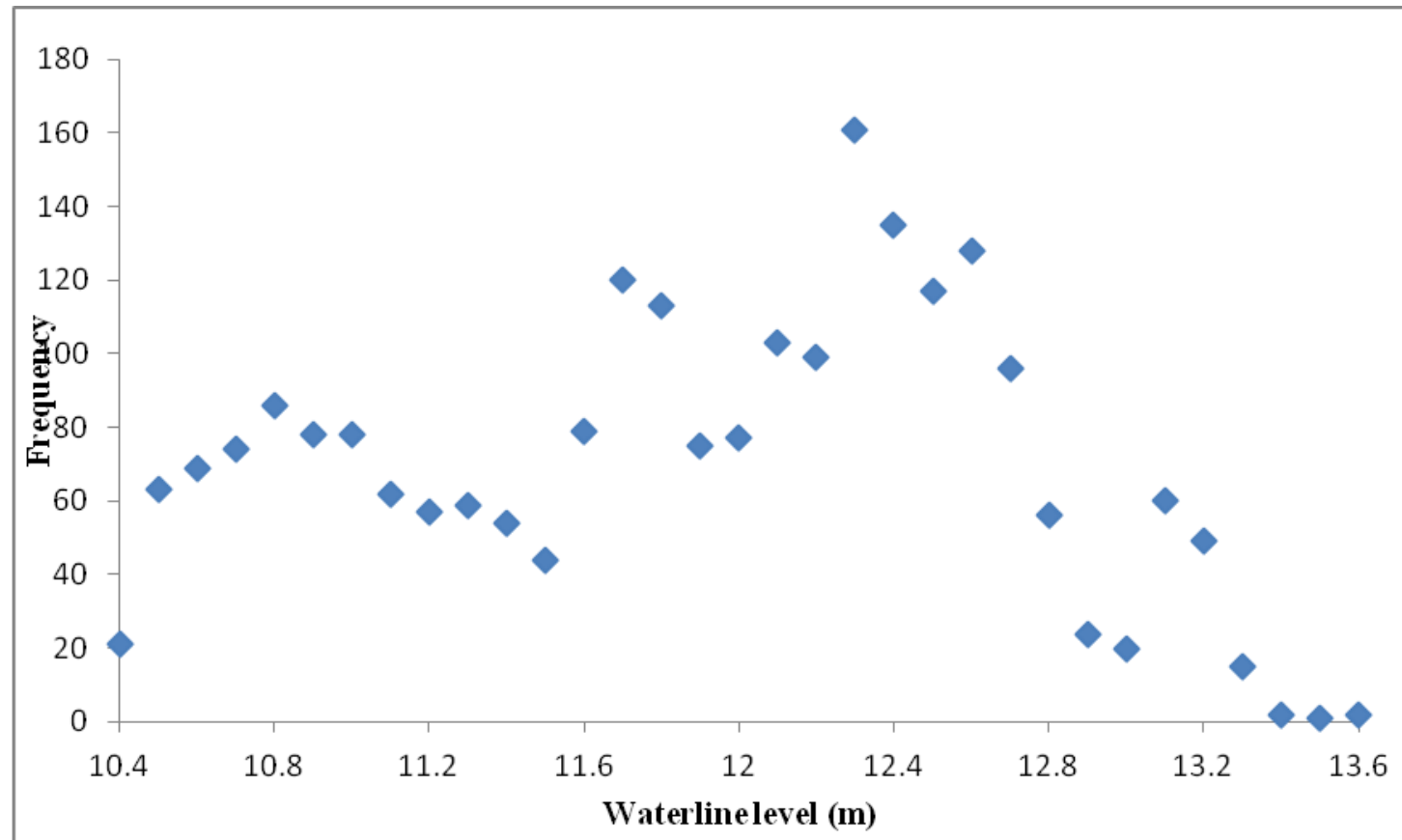

Figure 6. 


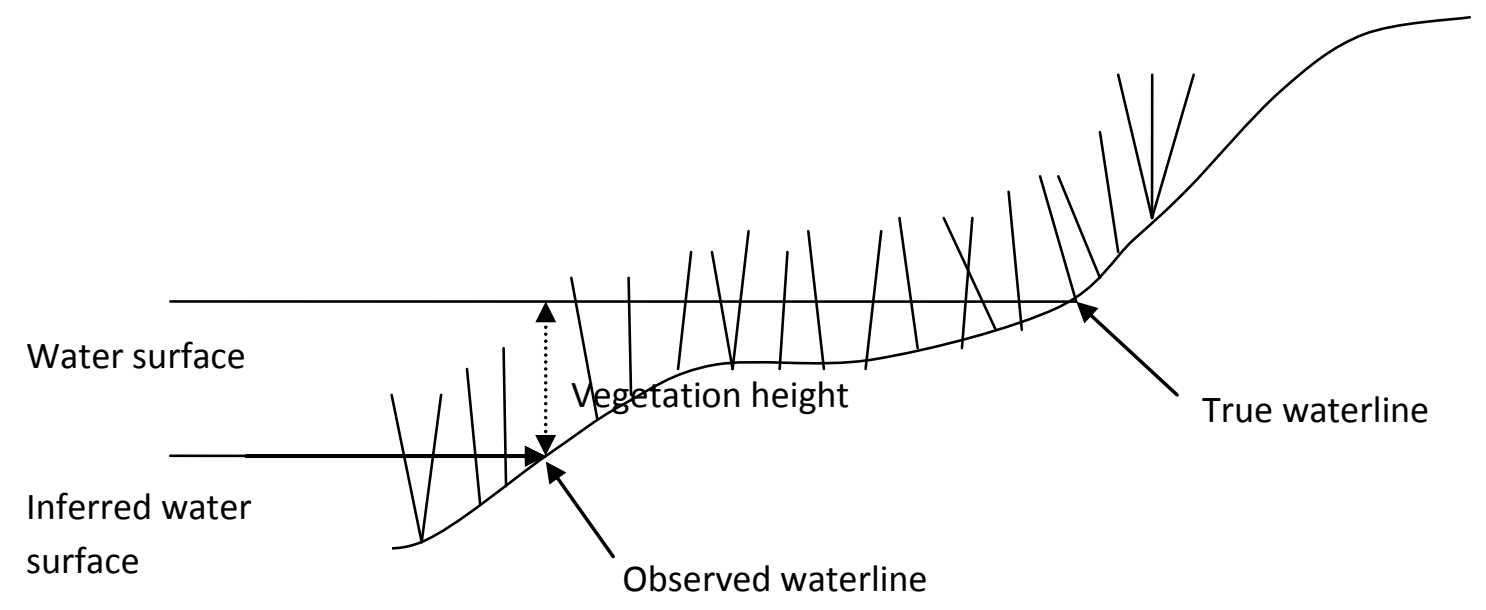

Figure 7. 


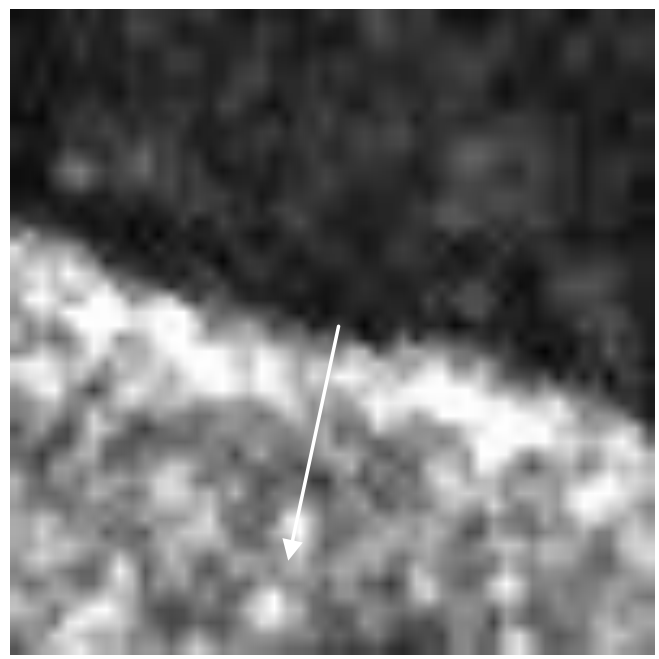

(a)

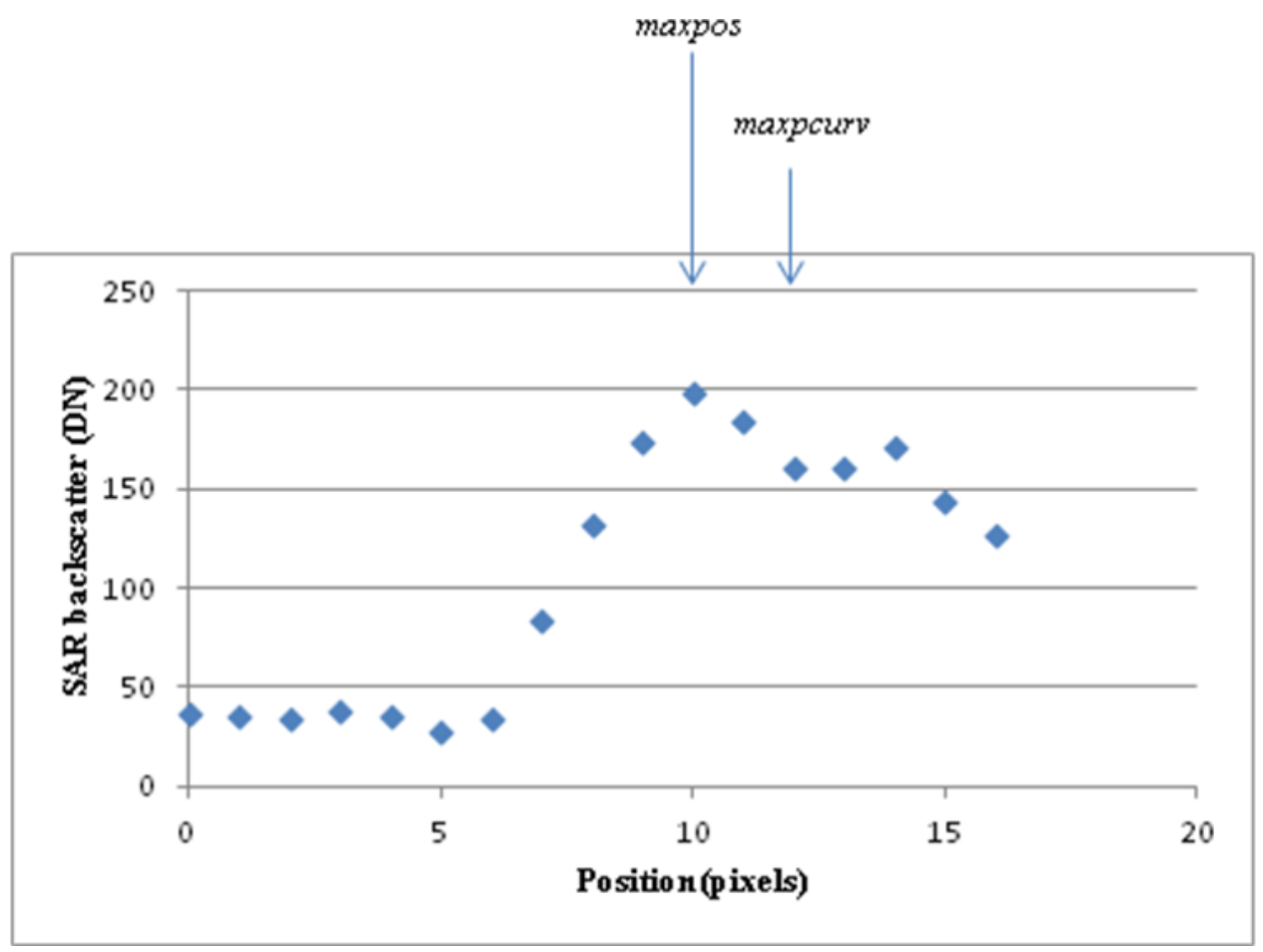

(b)

Figure 8. 


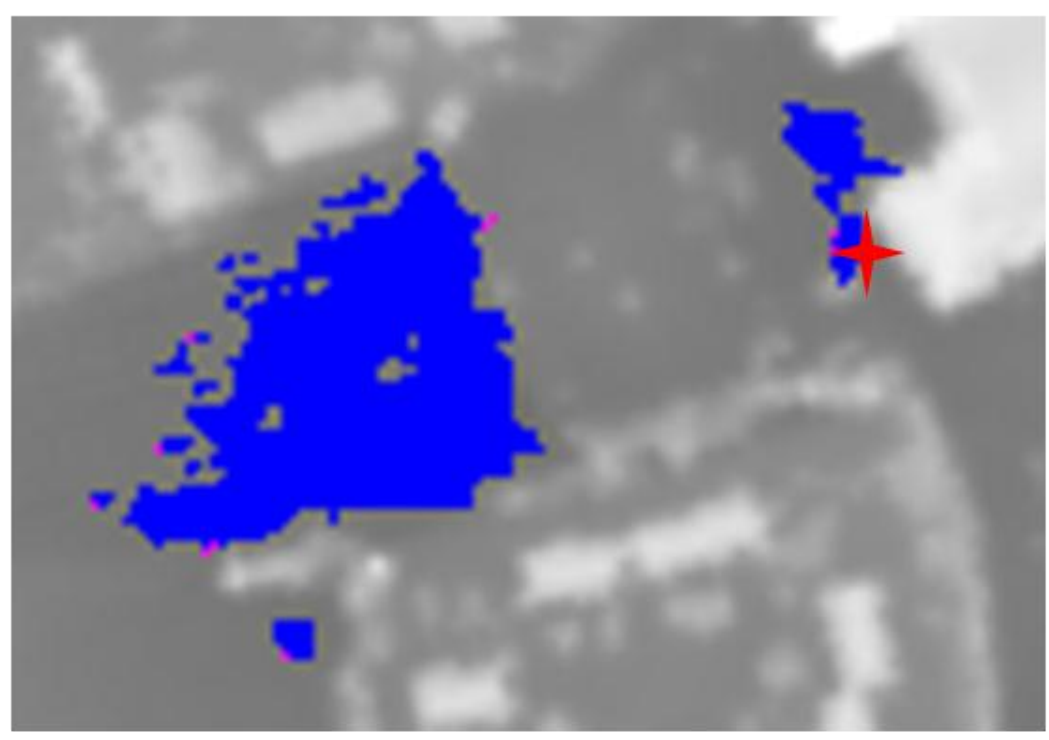

Figure 9. 


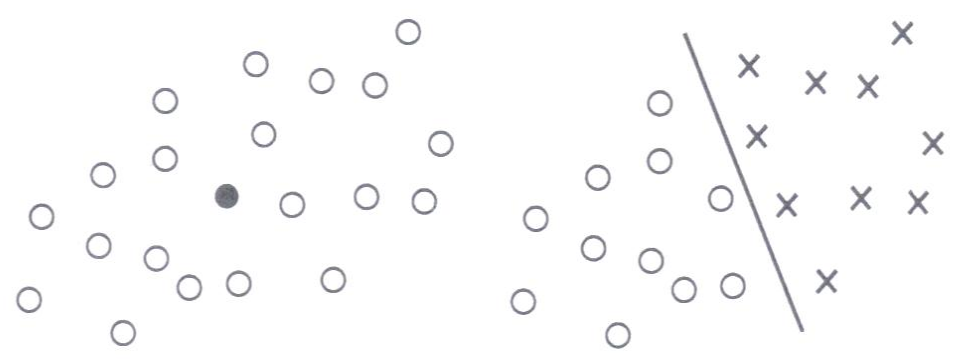

(a)

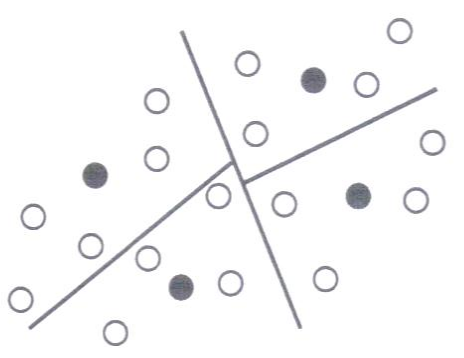

(c)

Figure 10. 


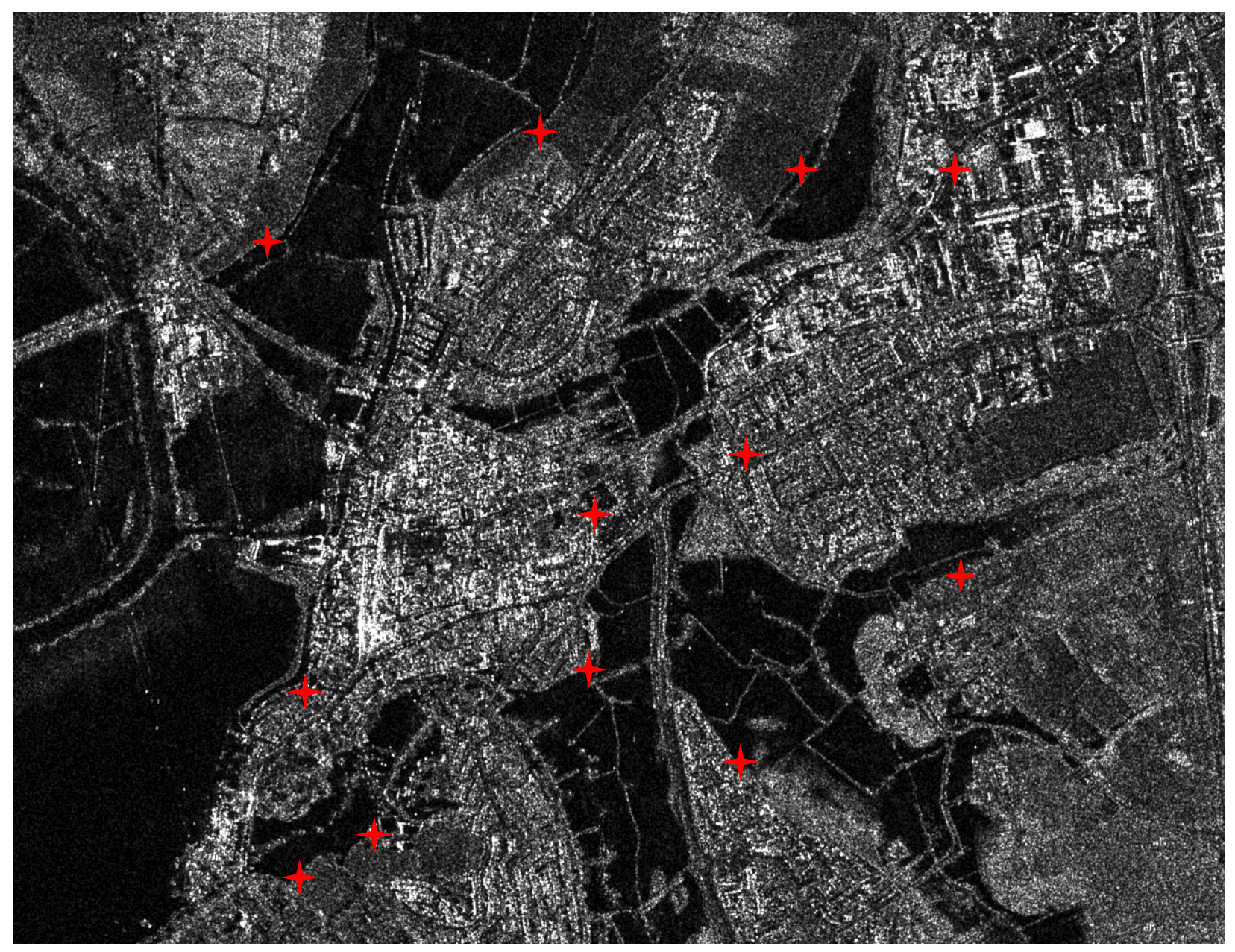

Figure 11a. 


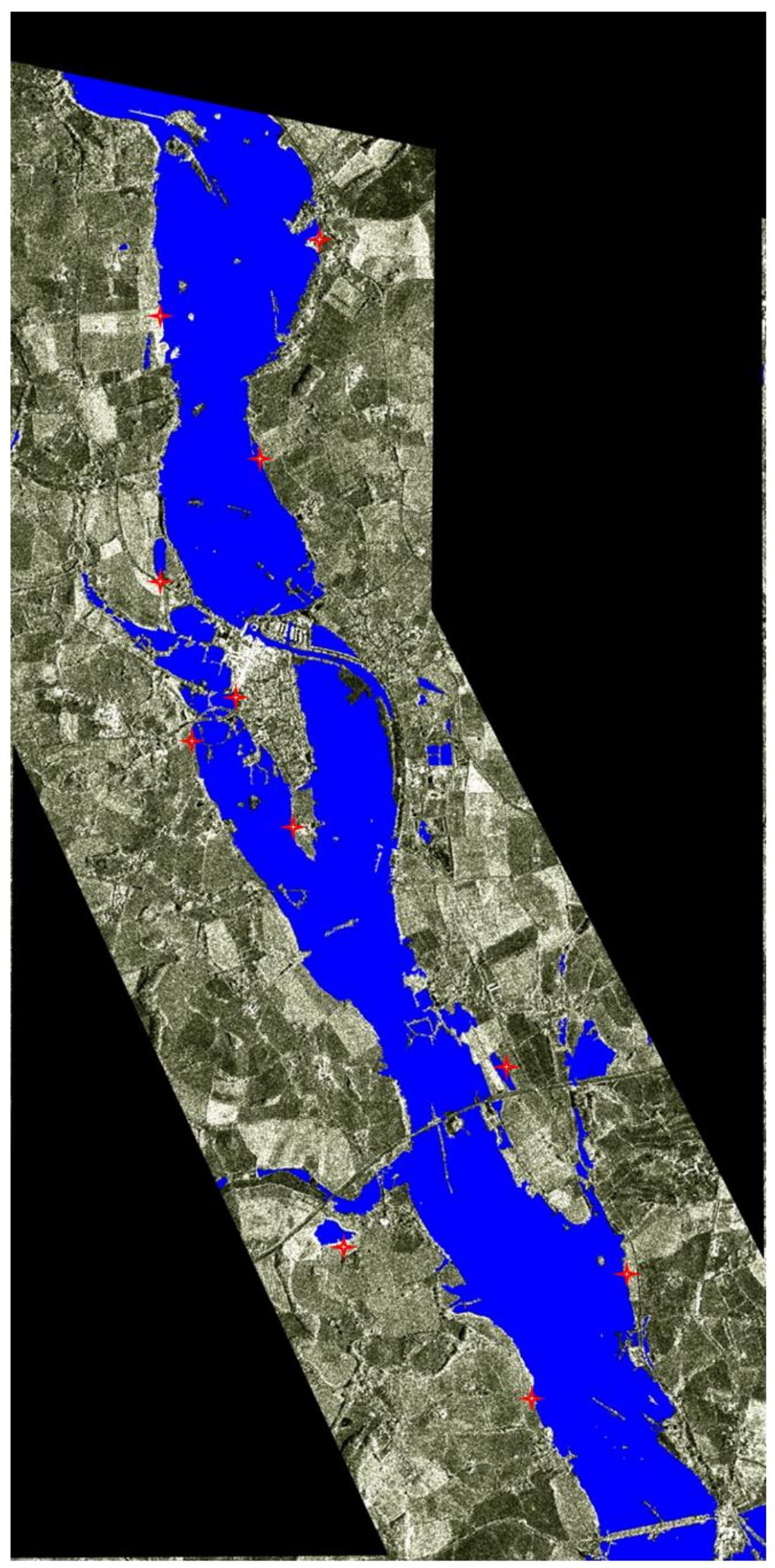

Figure $11 b$. 


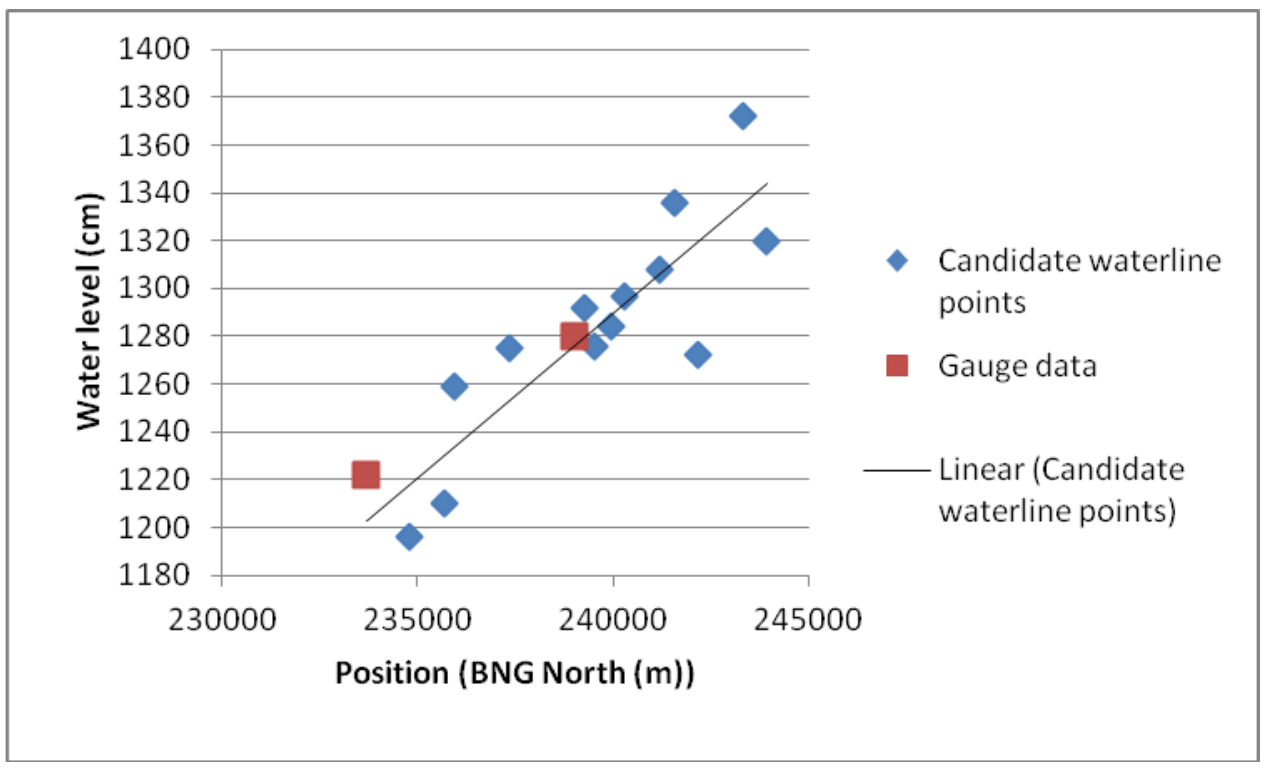

Figure 12. 